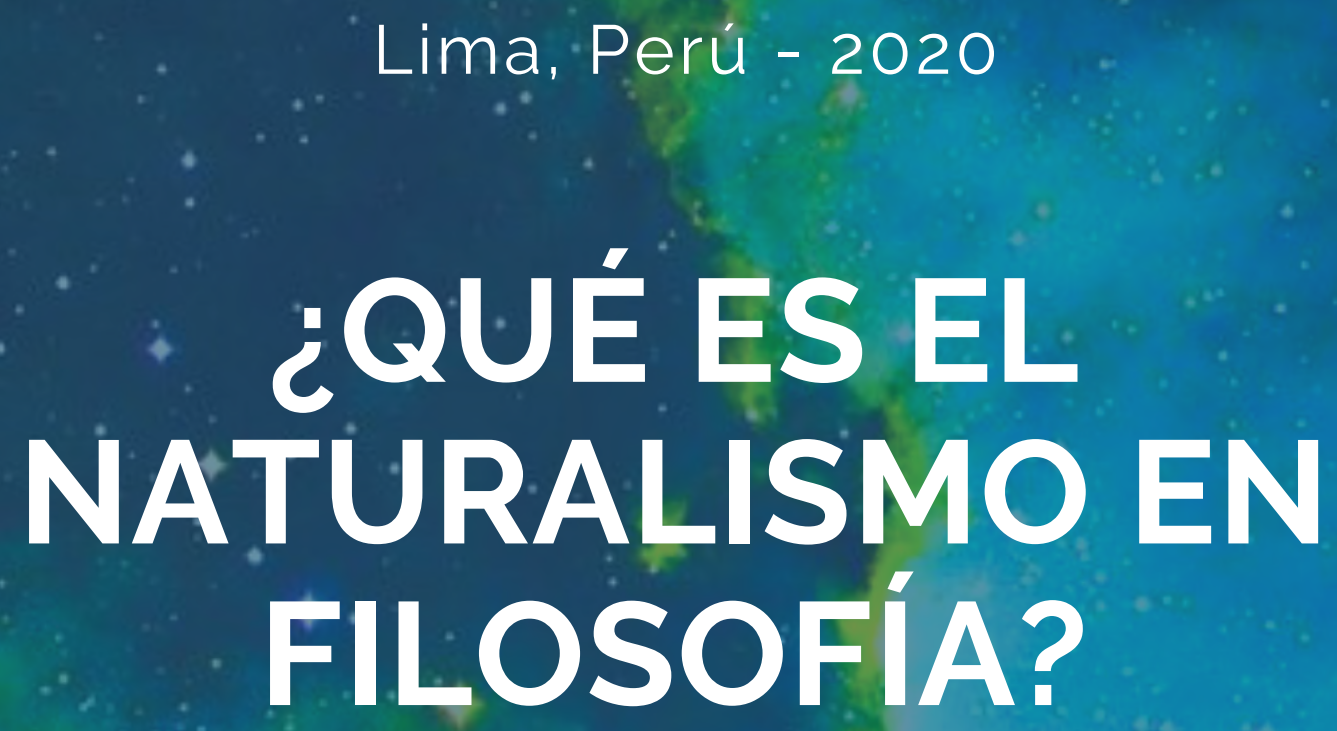

por

Henry Llanos Chilet

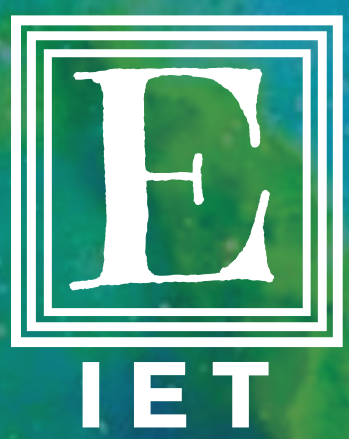

Instituto de Extrapolitica y Transhumanismo 


\title{
¿QUÉ ES EL NATURALISMO EN FILOSOFÍA?
}

\author{
por \\ Henry Llanos Chilet
}

\begin{abstract}
Resumen. El naturalismo es una corriente de pensamiento filosófica definida de múltiples maneras. A continuación se procederá a definir qué es el naturalismo y diferenciarlo de su contraparte: el sobrenaturalismo. Tras ello, se realizará un análisis de lo que implica lo sobrenatural y se expondrá la relación que existe entre la actitud naturalista y la filosofía materialista, de modo que se ponga de manifiesto la compatibilidad existente entre la ciencia y la filosofía naturalista.
\end{abstract}

Palabras clave: naturalismo, realismo, materialismo, filosofía, sobrenaturalismo, ciencia.

Sobre el Autor: Henry Llanos Chilet es Bachiller en ingeniería de sistemas y egresado de la Maestría de Filosofía de la Ciencia de la Universidad Nacional Mayor de San Marcos - Perú. Presidente de la Asociación Peruana de Ateos - APERAT. Miembro del Instituto de Extrapolítica y Transhumanismo (IET).

Imagen de Portada: Nebulosa NGC 6188 y el cúmulo estelar NGC 6193 - Partes de la Constelación Ara OB1 - Association in Hubble

\section{¿QUÉ ES EL NATURALISMO EN FILOSOFÍA?}

Puede definirse "naturalismo" como la actitud filosófica según la cual la Naturaleza y las cosas que la forman son las únicas realidades existentes. Esta definición es todavía problemática porque depende de otro concepto también problemático: el de "Naturaleza".

Según Ferrater Mora es más razonable restringir el término "naturalismo" a ciertas tendencias filosóficas modernas manifestadas durante los siglos XVIII, XIX y XX como el materialismo o el mecanicismo. Pero es muy importante saber que se puede ser naturalista sin ser materialista 0 mecanicista (Mora, 1979).

De acuerdo a Binder el término "naturalismo" identifica a aquellos filósofos que investigan temas eminentemente naturalistas basados en principios de origen o investigación natural. Ejemplo de esto es la primera escuela naturalista de Mileto de la Jonia Griega del s. VII A.C. (Binder, 2005) en la cultura occidental. 
El naturalismo, en filosofía, aparece como una negación del "sobrenaturalismo", que es la afirmación de que hay además de lo natural ("este mundo") algo sobrenatural (del "otro mundo"). En este sentido, según Mora, el naturalismo en anti-teológico (Mora, 1979).

Según Abbagnano el naturalismo es:

"la negación de toda distinción entre naturaleza y supranaturaleza y la tesis de que el hombre puede y debe ser comprendido, en todas sus manifestaciones, incluso en las consideraciones más altas (derecho, moral, religión, etc.) solo en relación con las cosas y los seres del mundo natural y por medio de los mismos conceptos usados por las ciencias para su explicación" (Abbagnano, 1993, pág. 843).

Confirmando pues la negación al sobrenaturalismo.

Regresando con Ferrater Mora, él sostiene que el naturalismo no es necesariamente una posición filosófica dogmática por tener más de "actitud" que de "doctrina". Vale decir que más se basa en un supuesto que en un conjunto de creencias específicas y estructuradas. Además, hace énfasis en dos variantes de naturalismo:

El naturalismo reduccionista materialista, según el cual:

"Consiste en sostener que todo lo que no parezca entidad natural deberá "reducirse" a una entidad natural o explicarse mediante una entidad natural. Las entidades naturales de que ahora hablamos no deben ser confundidas con los objetos de que se ocupan las ciencias naturales. Pueden ser, y son con frecuencia, entidades de que se ocupan las ciencias "humanísticas" y las ciencias sociales, y también entidades que son objeto de la experiencia cotidiana." (Mora, 1979, pág. 258)

Y el neo-naturalismo no-materialista y anti-esencialista que podría ser considerado como: "una de las reacciones contemporáneas de "la existencia contra la esencia", en particular la "esencia" tal como fue defendida por todos los que intentaron reducir la realidad a razón." (Mora, 1979, pág. 259). Esta otra vertiente piensa en términos de acontecimientos, eventos o cualidades que cambian permanentemente, o sea en termino de procesos sin ninguna sustancia "estática". La única reducción admitida aquí es la de lo sobrenatural a lo natural.

\section{Análisis de lo sobrenatural}

Pero qué es aquello que no es natural o está más allá de la naturaleza: pues nada más y nada menos que "lo sobrenatural". De la misma definición se infiere que todo lo sobrenatural es trascendente, donde "trascendencia" es la negación de la " inmanencia ", o sea no estar "localizado" dentro de los confines de nuestro mundo espaciotemporal.

Spiegelberg afirma que lo sobrenatural se caracteriza casi siempre en términos negativos de características naturales conocidas (Spiegelberg, 1951). Por ejemplo, la "primera causa" de la filosofía tomista, como aquella causa de otras cosas que a su vez no tiene una causa, sería algo sobrenatural. Los pocos atributos positivos de lo sobrenatural, como la omnipotencia o la omnisciencia, son en realidad propiedades naturales elevadas en un grado absoluto; o sea, no son completamente no-naturales, si no exageraciones de atributos naturales. 
Spiegelberg, pues, distingue dos concepciones de lo sobrenatural (Spiegelberg, 1951, pág. 343):

- Cuantitativo o sobrenatural propiamente dicho: donde las entidades sobrenaturales son propiedades que difieren de las naturales sólo en grado, aunque a menudo en un grado absoluto. Por ejemplo, una entidad sobrenatural es más poderosa que una entidad natural, incluso todopoderosa; o más conocedor, incluso omnisciente. Los atributos de las entidades sobrenaturales se conciben sobre la base de propiedades naturales antropomorfas. Lo que sugiere que lo "cuantitativamente sobrenatural", si es que lo hay, todavía tendría que ser espaciotemporal.

A pesar de muchas defensas teológicas, las nociones de omnipotencia y omnisciencia son incoherentes y se pueden hacer paradojas de ellas como la conocida "paradoja de la omnipotencia".

- Cualitativo o transnatural: donde las entidades sobrenaturales son categóricamente diferentes de las naturales (definidas negativamente), tanto que sus propiedades son misteriosas, inefables e incomprensibles. "Dios" es el totalmente "lo otro", no alguien que debe entenderse ni por la más mínima analogía con cualquier cosa natural conocida.

Entonces, mientras que lo sobrenatural parece ser algo inteligible por analogía con las propiedades naturales conocidas, lo transnatural es totalmente incomprensible. Para obtener un mínimo de inteligibilidad, las concepciones de lo sobrenatural en general combinan ambas características: sobrenaturales propiamente dichas y trasnaturales.

Esto le permite al creyente oscilar entre estas dos concepciones, dependiendo de sus necesidades argumentativas. La teología moderna tiende a rechazar una concepción meramente sobrenatural de lo sobrenatural por ser demasiado antropomórfica, y parece preferir una concepción más "sofisticada" de lo sobrenatural o transnatural (Manher, 2012).

\section{Relación con el Materialismo}

Toda relación entre corrientes siempre es problemática, ya que hay muchos autores que le dan distintos enfoques. Se puede decir que todos los materialistas tienen la actitud naturalista, pero no al revés: no todos los naturalistas son materialistas, como se puede deducir de las vertientes naturalistas no-materialistas de Ferrater Mora. Bunge afirma que mientras el materialismo admite "emergencia", el naturalismo tiene un carácter más reduccionista (Bunge, 2006): todo lo reduce a la "naturaleza" (aunque como dijimos, este término es muy problemático). Para muchos otros autores, como F. Mora, el reduccionismo se da en mayor medida en el materialismo que en el naturalismo.

Lo importante es notar que el materialismo tiene más de corriente filosófica que de actitud, a diferencia del naturalismo que tiene más de actitud o cosmovisión. Esto hace que las varias corrientes o tendencias filosóficas que son materialistas tengan posiciones claras y contenidos con distintos matices o tipos.

\section{Conclusiones}


Podemos concluir que el naturalismo es la actitud de creer que todo lo que existe (el universo, metafísicamente hablando) es "la naturaleza": se hace, pues, una relación de identidad entre "universo" y aquello problemático que es la "naturaleza". El naturalista también cree que el "universo-naturaleza" es un sistema perfectamente cerrado: no puede haber influencias o causas externas, que serían por definición "sobrenaturales", ya que sólo existe "lo natural". El naturalista también tiene la tendencia a creer que el universo-naturaleza se "mueve", en última instancia, por causas inmanentes y automáticas (inconscientes); las cuales generan comportamientos regulares (leyes) entre los entes naturales, sin lugar a excepciones. Esta es la razón por la que los naturalistas rechazan acontecimientos excepcionales a las leyes o regularidades como los "milagros" de las mitologías o religiones (además que estos tendrían causas sobrenaturales o externas con un agente consciente).

Los ejes centrales del naturalismo serían, entonces, la inmanencia y el automatismo.

El primer brote de naturalismo propiamente dicho en el mundo occidental, y tal vez en la historia de la humanidad, fue el de la ESCUELA DE MILETO en la Grecia jónica del siglo VII antes de nuestra era. Que haya surgido relativamente tarde en la historia humana y que los humanos hayamos estado inmersos mentalmente en ideas sobrenaturales desde nuestro ascenso como especie, nos habla de una tendencia animista en nuestra naturaleza biológica.

Por otro lado, el hecho de que la filosofía haya surgido en el seno del naturalismo (escuela de Mileto), que la ciencia haya nacido en el seno de la filosofía y a su vez la tecnología en el seno de la ciencia, nos habla de un naturalismo intrínseco en el corazón de todos los métodos y sistemas de conocimientos racionalistas.

\section{Referencias Bibliográficas}

Abbagnano, N. (1993). Diccionario de Filosofía. Mexico: Fondo de Cultura Económica.

Binder, H. (2005). Naturalismo y Filosofia: las visiones científicas de la realidad. Realidad: revista de ciencias sociales y humanidades, 435-459.

Bunge, M. (2006). Chasing reality. Strife over realism. Toronto: University of Toronto Press.

Manher, M. (2012). The Role of Metaphysical Naturalism in Science. Science \& Education, 1437-1459.

Mora, J. F. (1979). Diccionario de Filosofia Tomo II. Buenos Aires: Sudamericana.

Spiegelberg, H. (1951). Supernaturalism or naturalism: A study in meaning and verifiability. Philosophy of Science Vol. 18, 339-368. 